University of Nebraska - Lincoln

DigitalCommons@University of Nebraska - Lincoln

Identification of gene clusters associated with fusaric acid, fusarin, and perithecial pigment production in Fusarium verticillioides

\author{
Daren W. Brown \\ USDA-ARS, daren.brown@ars.usda.gov \\ Robert A. E. Butchko \\ USDA-ARS \\ Mark Busman \\ USDA-ARS \\ Robert H. Proctor \\ USDA-ARS
}

Follow this and additional works at: https://digitalcommons.unl.edu/usdaarsfacpub

Brown, Daren W.; Butchko, Robert A. E.; Busman, Mark; and Proctor, Robert H., "Identification of gene clusters associated with fusaric acid, fusarin, and perithecial pigment production in Fusarium verticillioides" (2012). Publications from USDA-ARS / UNL Faculty. 1581.

https://digitalcommons.unl.edu/usdaarsfacpub/1581

This Article is brought to you for free and open access by the U.S. Department of Agriculture: Agricultural Research Service, Lincoln, Nebraska at DigitalCommons@University of Nebraska - Lincoln. It has been accepted for inclusion in Publications from USDA-ARS / UNL Faculty by an authorized administrator of DigitalCommons@University of Nebraska - Lincoln. 


\title{
Identification of gene clusters associated with fusaric acid, fusarin, and perithecial pigment production in Fusarium verticillioides
}

\author{
Daren W. Brown*, Robert A.E. Butchko, Mark Busman, Robert H. Proctor \\ Bacterial Foodborne Pathogens and Mycology Research, USDA-ARS-NCAUR, 1815 N. University St., Peoria, IL 61604, USA
}

\section{A R T I C L E I N F O}

Article history:

Received 26 October 2011

Accepted 19 May 2012

Available online 29 May 2012

\section{Keywords:}

Secondary metabolism

Polyketide

Fusarium verticillioides

Microarray analysis

Fusaric acid

\begin{abstract}
A B S T R A C T
The genus Fusarium is of concern to agricultural production and food/feed safety because of its ability to cause crop disease and to produce mycotoxins. Understanding the genetic basis for production of mycotoxins and other secondary metabolites (SMs) has the potential to limit crop disease and mycotoxin contamination. In fungi, SM biosynthetic genes are typically located adjacent to one another in clusters of coexpressed genes. Such clusters typically include a core gene, responsible for synthesis of an initial chemical, and several genes responsible for chemical modifications, transport, and/or regulation. Fusarium verticillioides is one of the most common pathogens of maize and produces a variety of SMs of concern. Here, we employed whole genome expression analysis and utilized existing knowledge of polyketide synthase (PKS) genes, a common cluster core gene, to identify three novel clusters of co-expressed genes in $F$. verticillioides. Functional analysis of the PKS genes linked the clusters to production of three known Fusarium SMs, a violet pigment in sexual fruiting bodies (perithecia) and the mycotoxins fusarin $\mathrm{C}$ and fusaric acid. The results indicate that microarray analysis of RNA derived from culture conditions that induce differential gene expression can be an effective tool for identifying SM biosynthetic gene clusters.
\end{abstract}

Published by Elsevier Inc.

\section{Introduction}

Fungal secondary metabolite (SM) biosynthetic genes are typically located adjacent to each other (e.g. in a cluster) and tend to exhibit similar patterns of expression (Keller et al., 2005; Shwab and Keller, 2008). This tightly controlled regulation has been suggested as a main selective force for gene clustering (Khaldi and Wolfe, 2011). SM gene clusters usually include a core synthase gene responsible for synthesis of the SM parent chemical, genes responsible for chemical modifications (e.g. oxidoreduction, acyl or amino transfer, and dehydrogenation), one or more genes involved in transport of the SMs, and one or more genes that regulate cluster gene transcription. Most core synthase genes encode either a polyketide synthase (PKS), non-ribosomal peptide synthetase (NRPS), or terpene cyclase (TC). Multiple methods have been used to identify SM biosynthetic gene clusters including over expression of transcriptional regulators located proximal to core genes, heterologous expression of the core synthase gene, altering cluster transcription by modifying chromatin structure (Bok et al., 2009; Chiang et al., 2009; Watanabe et al., 1999) and the bioinformatic (e.g. SMURF or Secondary Metabolite Unknown Regions Finder) identification of multiple SM genes located adjacent to a core gene by homology (Khaldi et al., 2010). The number of core synthase

\footnotetext{
* Corresponding author. Fax: +1 3096816672.

E-mail address: daren.brown@ars.usda.gov (D.W. Brown).
}

genes per fungal genome (Ma et al., 2010; Yoder and Turgeon, 2001) suggest that many fungal species can produce up to 10 fold more SMs than indicated by chemical analysis. In accordance with this genetic potential, fungi in the genus Fusarium have been found to produce a wide variety of SMs that are diverse in structure and biological activity. The most thoroughly studied Fusarium SMs are the mycotoxins, fumonisins, trichothecenes, and zearalenone. These SMs pose a threat to human and animal health because consumption of contaminated grain or grain-based food and feed has been associated with a variety of diseases (Glenn, 2007; Morgavi and Riley, 2007). The economic impact of these mycotoxins on health costs and effect on international trade is estimated to be in the $100 \mathrm{~s}$ of millions of dollars each year (Wu, 2007).

Fusarium verticillioides is one of the most common maize-associated fungi worldwide and can infect and colonize maize as an endophyte (i.e. without causing disease symptoms) or as a pathogen (i.e. causing symptoms). During growth on maize, the fungus can produce fumonisins and a number of other polyketidederived SMs, including the toxins fusaric acid (5-butylpicolinic acid) and fusarins, the pigment bikaverin, and an uncharacterized violet pigment present in the walls of sexual fruiting bodies (perithecia). Production of these metabolites has been reported in other, but not all, Fusarium species as well as in other fungal genera. For example, fumonisin production has been reported in several Fusarium species within the Gibberella fujikuroi species complex (GFSC), in rare isolates of the closely related species 
Fusarium oxysporum (Proctor et al., 2004), and in Aspergillus niger (Frisvad et al., 2007) and Tolypocladium (Mogensen et al., 2011). In contrast, fusarin production occurs across a genetically broad range of Fusarium species including multiple GFSC and trichothecene-producing species (Desjardins and Proctor, 2001; Proctor et al., unpublished).

The role of these SMs in the ecology of Fusarium is not clear. However, they do exhibit varying levels of toxicity to plants and animals. For example, fumonisins affected maize sphingolipid synthesis and pathogenesis of $F$. verticillioides in some maize seedling assays (Glenn et al., 2008; Myung et al., 2011). However, they did not affect pathogenesis in other maize seedling assays or in an ear rot assay (Desjardins et al., 2007; Desjardins et al., 2002). Fumonisin consumption can cause a variety of diseases in animals and is epidemiologically associated with esophageal cancer and neural tube defects in humans (Gonzalez et al., 1999; Marasas et al., 2004). Fusaric acid is a broad-spectrum plant toxin and is thought to contribute to the severity of $F$. oxysporum-induced vascular wilt, damping-off and root rot diseases of numerous vegetable crops (Capasso et al., 1996). Fusaric acid is considered a mild toxin to mammals (Bacon et al., 1996). In contrast, fusarins have been reported to be mutagenic in the Ames Salmonella mutagenicity assay (Gelderblom et al., 1983; Gelderblom et al., 1984) but not carcinogenic in mouse and rat model systems (Gelderblom et al., 1986). Recently, it has been reported that fusarin $C$ stimulates growth of a breast cancer cell suggesting that it acts as an estrogenic mimic (Sondergaard et al., 2011). Initial studies with fusarin-nonproducing $F$. verticillioides strains in maize seedling and ear rot assays indicate that they are not required for pathogenesis (Brown and Proctor, unpublished). Fusarium pigments (e.g. the naphthoquinones bikaverin and fusarubin) are best known for the protective role they provide fungi against environmental stresses such as bacteria and plants (Medentsev and Akimenko, 1998). Overall, fumonisins, fusarins, fusaric acid and bikaverin may contaminate maize and maize-based food and feed and as a result, pose a risk to human and livestock health.

Examination of the genetics of Fusarium SM biosynthesis is motivated by the need to limit mycotoxin contamination of agricultural products and to understand how SMs impact Fusariuminduced plant disease. Analysis of $F$. verticillioides genome sequence identified 16 genes predicted to encode PKSs (Kroken et al., 2003; Ma et al., 2010). The functions of two of these genes have been assigned based on studies in F. verticillioides: FUM1 (PKS11) is required for fumonisin production (Proctor et al., 1999) and PGL1 (PKS3) is required for production of the violet perithecial pigment (Proctor et al., 2007). The function of two more have been assigned based on studies in closely related Fusarium species: PKS4 is required for bikaverin production (Fusarium fujikuroi) (Wiemann et al., 2009) and PKS10 is required for fusarin C production (Fusarium moniliformis and Fusarium venenatum) (Song et al., 2004) and Fusarium graminearum (Gaffoor et al., 2005). To date, associated gene clusters have been identified for two of the PKS genes: FUM1 (Proctor et al., 2003) and BIK1 (Brown et al., 2008) based on gene expression and/or gene inactivation analysis.

The identification of multiple SMs that are likely derived from polyketides combined with the identification of the remaining PKS genes in the $F$. verticillioides genome (Desjardins and Proctor, 2007) provides an excellent opportunity to identify additional PKS gene-containing clusters and link them to production of specific SMs. The overall goal is to better understand the role of SMs in the life of $F$. verticillioides; in particular, with regards to the maize disease process. Thus, in the current study, we employed microarray analysis to identify clusters of co-expressed genes that include a PKS gene. The analysis confirmed the existence of the two previously described biosynthetic gene clusters and provided evidence for three heretofore uncharacterized clusters. In addition, results of functional analysis conducted here and previous studies linked the three novel clusters to production of the SMs fusarins, the violet perithecial pigment, and fusaric acid. The identification of these clusters will facilitate future analyses of whether the SMs have a role in plant pathogenesis.

\section{Materials and methods}

\subsection{Strains and media}

The wild-type strain of $F$. verticillioides used in this study was M-3125 (NRRL 13447) (Leslie et al., 1992). RNA was prepared from cultures grown in GYAM $(0.24 \mathrm{M}$ glucose, $0.05 \%$ yeast extract, $8 \mathrm{mM}$ L-asparagine, $5 \mathrm{mM}$ malic acid, $1.7 \mathrm{mM} \mathrm{NaCl}, 4.4 \mathrm{mM}$ $\mathrm{K}_{2} \mathrm{HPO}_{4}, 2 \mathrm{mM} \mathrm{MgSO}_{4}$, and $8.8 \mathrm{mM} \mathrm{CaCl}_{2}$, pH 3.0) medium for 12 , $24,48,72,96$ or $120 \mathrm{~h}$. Fusaric acid and fusarin production by $F$. verticillioides was determined from cracked maize kernel medium cultures grown for 10 days at $25^{\circ} \mathrm{C}$. The medium was prepared by autoclaving $2.5 \mathrm{~g}$ of cracked maize kernels and $1.2 \mathrm{~mL}$ of distilled water in a 4-dram glass vial. Each vial was inoculated with a single mycelial plug taken from a V-8 juice agar (Tuite, 1969) culture of $F$. verticillioides.

\subsection{Gene identification}

Tentative functions of proteins encoded by open reading frames (ORFs) flanking FVEG_11086 and FVEG_12523 were assigned based on BLAST searches of the non-redundant sequence databases, using the default parameters, at the National Center for Biotechnology Information (NCBI) (Tables 2 and 3) (Altschul et al., 1997). F. verticillioides and $F$. graminearum genomic nucleotide sequences were retrieved from the Fusarium Comparative database at the Broad Institute (http://www.broadinstitute.org/ annotation/genome/fusarium_group/MultiHome.html). Transcript sequences were retrieved from the $F$. verticillioides Gene Index database at the Dana-Farber Cancer Institute (http://compbio. dfci.harvard.edu/tgi/cgi-bin/tgi/gimain.pl?gudb=f_verticill) (Brown et al., 2005). Fusarium solani (teleomorph Nectria haematococca) genomic nucleotide sequences were retrieved from the Joint Genome Institute's fungal genome database (http://genome.jgi-psf.org/ Necha2/Necha2.home.html). All sequences were assembled using Sequencher ${ }^{\mathrm{TM}}$ (version 4.10.1, Gene Codes Corp., Ann Arbor, MI) and examined manually.

\subsection{DNA preparation and PCR amplification}

DNA was prepared for PCR analysis as previously described (Butchko et al., 2003) with only minor modifications. Mycelia were scraped from one-week-old V-8 juice agar plates, placed in $250 \mu \mathrm{l}$ of DNA extraction buffer (200 mM Tris, pH 8.0, $250 \mathrm{mM} \mathrm{NaCl}$, $25 \mathrm{mM}$ ethylenediaminetetraacetic acid, and 0.5\% SDS), and incubated $10 \mathrm{~min}$ at $65^{\circ} \mathrm{C}$. Organic material was separated by the addition of $250 \mu \mathrm{l}$ of phenol:chloroform:isoamyl alcohol (25:24:1) to the mixture, followed by vortexing and centrifugation. The aqueous phase was transferred to a new tube and genomic DNA was isolated using UltraBind following the manufacturer's directions (Mo Bio, Solana Beach, CA). PCR was performed with a total reaction volume of $10 \mu \mathrm{l}\left(5 \mu \mathrm{l}\right.$ Promega GoTaq ${ }^{\circledR}$ master mix, $1 \mu \mathrm{l}$ of each primer $(10 \mu \mathrm{M})$, and $50 \mathrm{pg}$ of genomic DNA) in a MJ Research PTC-100 PCR thermocycler (Waltham, MA) with the following program: $95^{\circ} \mathrm{C}$ for $30 \mathrm{~s}$ followed by $57^{\circ} \mathrm{C}$ for $30 \mathrm{~s}$ followed by $72^{\circ} \mathrm{C}$ for $90 \mathrm{~s}$ for 30 cycles. 
Table 1

Primers used in this study.

\begin{tabular}{ll}
\hline $\begin{array}{l}\text { Primer } \\
\text { name }\end{array}$ & Sequence 5'-3' $^{\prime}$ \\
\hline P6F & CCATTGCCTAGTTAGCTGATAG \\
P6LFI & GTCGTGACTGGGAAAACCTGGCGCGAGCCATTGGAGAGAGTCAT \\
P6RFI & TCCTGTGTGAAATTGTATCCGCTGTCAAGCGTGAGACCAATAGCAC \\
P6RF & GAAGTCTCTTCGTCGGCAGG \\
P6FN & CTCTAAGCGACATATCTCTAC \\
P6RFN & CTACCTTGAAGCTCTTCAGC \\
P6T2F1 & CACTAGCAACGGCCATGGAG \\
P6T2R1 & CAGCTACAGAATGTCAGCTC \\
P6RFO1 & GTGAGGTCAAGCTTCTCCTG \\
P6LFO1 & CTGTGAGTTTCCTTACCAGC \\
P6TF & ATGACTCTCTCCAATGGCTC \\
P6TR & GTGCTATTGGTCTCACGCTTG \\
M13FL & CGCCAGGGTTTCCCAGTCACGAC \\
M13RL & AGCGGATAACAATTTCACACAGGA \\
HY & GGATGCCTCCGCTCGAAGTA \\
YG & CGCCAGGGTTTCCCAGTCACGAC \\
HYN & GCGCGTCTGCTGCTCCATAC \\
YGN & CCGAACTGCCCGCTGTTCTGC \\
Hygout1 & CACGGTGCCTGACTGCGTTAGC \\
Hygout2 & GGTGGGCCTTGACATGTGCAGC \\
719 & GACGTTGTAAAACGACGGCCAGTG \\
878 & GCAACGGCTCTTGCTTGAAGCTGT \\
879 & CAGTGAAGAAGGCTTCGTGAATAGC \\
1098 & ACCAAGCCTATGCCTACAGCATCC \\
\hline
\end{tabular}

\subsection{Microarray analysis}

Microarrays were designed and produced by Roche NimbleGen (Madison, WI) based on 12,414 gene models obtained from the
Broad Institute in January, 2008 and 875 unique ESTs from the $F$. verticillioides Gene Index. Each sequence was represented on the array by up to 12 unique 60 -mer probes. Total RNA was extracted using the RNeasy Mini kit (Qiagen Inc., Valencia, CA). DNA was removed by on-column DNase digestion with the RNase-Free DNase set (Qiagen Inc., Valencia, CA). Microarray hybridization, data acquisition and initial analysis were conducted by Roche NimbleGen, Iceland. Data were normalized by robust multiarray average (Bolstad et al., 2003; Irizarry et al., 2003) and were compared using the Acuity 4.0 microarray analysis software package (Molecular Devices Corp, Sunnyvale, USA). The GYAM experiment (Gene Expression Omnibus (GEO) accession no. GSE16900) was conducted with three biological replicas for the wild-type strain after 24, 48, 72 and $96 \mathrm{~h}$.

\subsection{Northern analysis}

Total RNA was isolated from wild-type $F$. verticillioides via the TRIzol method (Gibco BRL, Gaithersburg, MD) and Northern blots were carried out as previously described (Proctor et al., 2003). DNA probes for hybridization were labeled with $\left[{ }^{32} \mathrm{P}\right] \mathrm{dCTP}$ with the Prime-A-Gene system (Promega, Madison, WI). DNA templates used to synthesize hybridization probes consisted of 700-1200-bp fragments amplified by PCR from $F$. verticillioides genomic DNA with specific primers. PCR Primers were designed based on predicted gene models FVEG_11075FVEG_11092 from the Broad Institute's F. verticillioides genome sequence database.

Table 2

FUS cluster, flanking genes, and predicted function.

\begin{tabular}{|c|c|c|c|c|c|}
\hline F. verticillioides $\mathrm{FCD}$ designation ${ }^{\mathrm{a}}$ & Gene name & Protein (AAs) & Predicted function $^{\mathrm{b}}$ & BLAST $^{\mathrm{C}} \mathrm{E}$ value & Accession \\
\hline FVEG_11077 & - & 415 & Unknown ${ }^{\mathrm{c}}$ & - & - \\
\hline FVEG_11078 & FUS9 & 355 & Methyltransferase & $5 \times 10^{-14}$ & ACG28379 \\
\hline FVEG_11079 & FUS8 & 514 & Monooxygenase & 0.0 & AA073449 \\
\hline FVEG_11080 & FUS7 & 461 & Dehydrogenase & $2 \times 10^{-90}$ & ADK93993 \\
\hline FVEG_11081 & FUS6 & 563 & MFS transporter & 0.0 & EFY96024 \\
\hline FVEG_11082 & FUS5 & 233 & Oxidoreductase & $3 \times 10^{-25}$ & EDU39826 \\
\hline FVEG_11083 & FUS4 & 439 & Protease & $1 \times 10^{-5}$ & BAH20542 \\
\hline FVEG_11084 & FUS3 & 220 & Regulation & $3 \times 10^{-36}$ & AAH54190 \\
\hline FVEG_11085 & FUS2 & 419 & Hydrolase & $2 \times 10^{-176}$ & EFY96027 \\
\hline FVEG_11086 & FUS1 & 3734 & PKS-NRPS & 0.0 & AAT28740 \\
\hline FVEG_11087 & GHY1 & 283 & Glycosyl hydrolase & $6 \times 10^{-13}$ & CBN78991 \\
\hline
\end{tabular}

${ }^{a}$ FCD refers to the Fusarium Comparative Database at the Broad Institute. Bolded genes are co-expressed during growth in GYAM. Non-bolded genes that flank the cluster do not have EST support.

b Predicted functions are based on results of BLAST analysis.

c BLAST E value refers to the probability score, generated by BLASTX of each gene against the NCBI database, to the predicted protein with the associated accession number.

Table 3

FUB cluster, flanking genes, and predicted function.

\begin{tabular}{|c|c|c|c|c|c|}
\hline F. verticillioides FCD designation ${ }^{a}$ & Gene name & Protein (AAs) & Predicted function $^{\mathrm{b}}$ & BLAST E value $^{\mathrm{c}}$ & Accession \\
\hline FVEG_12524 & EST1 & 507 & Esterase & $2 \times 10^{-83}$ & ABK62698 \\
\hline FVEG_12523 & FUB1 & 2409 & PKS & 0.0 & AAR92213 \\
\hline FVEG_12522 & FUB2 & 109 & Unknown & - & - \\
\hline FVEG_12521 & FUB3 & 510 & Aspartokinase & $4 \times 10^{-145}$ & XP_961274 \\
\hline FVEG_12520 & FUB4 & 267 & Hydrolase $^{\mathrm{d}}$ & $6 \times 10^{-10} ; 8 \times 10^{-13} ; 6.5 \times^{-17}$ & XP_002909515; Pfam03959 \\
\hline FVEG_12519 & FUB5 & 463 & Acetyltransferase & $4 \times 10^{-130}$ & AAL09833 \\
\hline $\mathrm{NP}^{\mathrm{e}}$ & FVX1 & 152 & Unknown & - & - \\
\hline FVEG_12518 & HET1 & 1253 & $\mathrm{HET}^{\mathrm{f}}$ & $2 \times 10^{-115}$ & Q00808 \\
\hline
\end{tabular}

a FCD refers to the Fusarium Comparative Database at the Broad Institute. Bolded genes are co-expressed during growth in GYAM.

b Functions listed are based on the results of BLAST analysis.

c BLAST E value refers to the probability score, generated by BLASTX of each gene against the NCBI database, to the protein with the associated accession number.

d The first E value refers to BLASTX analysis while the second and third E values refer to BLASTP to the accession and to the pfam group indicated respectively.

e $\mathrm{NP}=$ not predicted. The putative gene was predicted based on the presence of an ORF.

${ }^{\mathrm{f}} \mathrm{HET}=$ vegetative incompatibility protein HET or beta transducin-like protein. 


\subsection{FVEG_11086 inactivation}

FVEG_11086 was inactivated with the integrative disruption strategy and the protoplast-mediated transformation method with the antibiotic hygromycin B ( $H y g B)$ as the selectable marker (Proctor et al., 2007; Proctor et al., 1999; Turgeon et al., 1987). The disruption vector (pPKS10 $\Delta / \mathrm{Hyg}$ ) was created by cloning a 652-bp fragment (nucleotides 339-990) of FVEG_11086, encoding a portion of the putative ketosynthase domain, into vector pUCH2-8, which contains the $H y g B$ resistance cassette (Alexander et al., 1998; Turgeon et al., 1987). A single, homologous recombination event between the FVEG_11086 coding region and the corresponding region of pPKS10 $\Delta / \mathrm{Hyg}$ would inactivate FVEG_11086 by generating two truncated copies of the coding region separated from one another by the disruption vector as previously described for PGL1 disruption (Proctor et al., 2007). Hygromycin-resistant transformants were screened for integration of pPKS10 $\Delta /$ Hyg into FVEG_11086 by PCR that employed primers that flanked the 652-bp fragment (primers 878 and 879 ) and were complementary to either the vector sequence (primer 719) or to the 3' end of $\operatorname{HygB}$ (primer 1098). In PCR, primer pair $878-879$ was expected to yield a 780 -bp amplicon from wild-type DNA and a $>6-\mathrm{kb}$ amplicon from transformants in which pPKS10 $\Delta /$ Hyg integrated into FVEG_11086 by a single homologous integration event. Primer pair 878-719 was expected to yield a 880-bp amplicon from FVEG_11086 disruption mutants but no amplicon from the wild type. Likewise, primer pair 879-1098 was expected to yield a 920-bp amplicon from FVEG_11086 mutants but no amplicon from the wild type (Supplemental Fig. 1). Disruption of FVEG_11086 was confirmed by Southern blot analysis using essentially the same strategy described previously for analysis of PGL1 disruption (Proctor et al., 2007). Primers used in this study are listed in Table 1.

\subsection{FVEG_12523 deletion}

Mutation of FVEG_12523 was accomplished by deletion of about half of its predicted coding region via the split-marker and protoplast transformation method with $\mathrm{HygB}$ as the selectable marker (Catlett et al., 2002; Proctor et al., 1999). The disruption amplicons were created by first amplifying two $\sim 800-$ bp fragments from wild-type $F$. verticillioides genomic DNA. The first fragment (Fub1-upstream) corresponded to an 800-bp region upstream of the FVEG_12523 start codon and was amplified with primer pair P6F-P6LFI. The second fragment (Fub1-dowstream) corresponded to an 800 -bp region that began $3.5 \mathrm{~kb}$ downstream of the FVEG_12523 start codon and was amplified with primer pair P6RFI-P6RF. Also, two fragments corresponding to overlapping regions of the $H y g B$ gene were amplified from plasmid pHygAsc (Brown et al., 2002). The first fragment ( $\underline{\text { Hyg- }}$ 5') included the 5' two thirds of the HygB gene and was amplified with primer pair M13FL-HY; and the second fragment (Hyg3') included the 3' two thirds of $\operatorname{HygB}$ and was amplified with primer pair M13RL-YG. Fragments Fub1-upstream and Hyg-3' were fused by PCR using nested primers P6FN and HYN. Likewise, fragments Fub1-downstream and Hyg-5' were fused using nested primers P6RFN and YGN. Integration of the two PCR products into the genome via three homologous recombination events was expected to replace $3.5 \mathrm{~kb}$ of the FVEG_12523 coding region with $\operatorname{HygB}$ (Catlett et al., 2002). Hygromycin-resistant transformants were screened by PCR to determine whether targeted DNA had been deleted and replaced with $\operatorname{HygB}$ and then to determine whether homologous recombination events had occurred as predicted. In the first case, PCR with primers P6T2F1 and P6T2R1 was expected to yield a 500-bp amplicon from wild-type DNA and no amplicon from transformants in which the $\operatorname{HygB}$ cassette replaced a $3.5 \mathrm{~kb}$ portion of FVEG_12523. Second, PCR with primer pairs P6RFO-Hygout1 and P6LFO1-Hygout2 were expected to yield no amplicons from wild-type DNA and $\sim 900$ and $\sim 940$-bp amplicons respectively from FVEG_12523 disruption mutants (Supplemental Fig. 2).

\subsection{Analysis of fusarin $C$ and fusaric acid}

For fusarins, a liquid chromatography-tandem mass spectrometry (LC-MS/MS) method similar to that described by Kleigrewe et al. (2011) and Maragos et al. (2008) was employed to monitor and quantify fusarin $C$, the fusarin analogue produced in greatest abundance by wild-type $F$. verticillioides. Care was taken to minimize exposure of samples to conditions previously shown to prompt isomerization. Fusarins were extracted from $2.5 \mathrm{~g}$ cracked maize cultures with $12 \mathrm{~mL}$ of acetonitrile/water (84\% $\mathrm{v} / \mathrm{v})$. Cultures were allowed to steep for $2 \mathrm{~h}$, with gentle shaking, and then filtered through a $0.45-\mu \mathrm{m}$-pore-size Gelman filter. The culture extracts were then analyzed for fusarin C by LC-MS/MS. The analytical method utilized a LC-MS/MS instrument consisting of a ThermoSpetraPhysics high performance liquid chromatography (HPLC) system and a ThermoFinnigan LCQ DECA ion trap mass spectrometer. The mass spectrometer was operated in positive mode utilizing an electrospray ionization (ESI) interface. Injections of $10 \mu \mathrm{l}$ of analyte were eluted from a Metachem (Torrance, CA, USA) Inertsil C18 $3 \times 150 \mathrm{~mm}$ column with a $300 \mu \mathrm{l} / \mathrm{min}$ gradient flow of water/methanol $(\mathrm{MeOH})$. The entire column flow was directed to the ESI interface of the mass spectrometer. HPLC solvents were acidified with $0.3 \%$ acetic acid. The gradient program consisted of the following steps: $0-10 \mathrm{~min}$, 35\% $\mathrm{MeOH}$; 10-25 min, 35-95\% $\mathrm{MeOH} ; 25-26 \mathrm{~min}, 95 \% \mathrm{MeOH}$; 26-34 min, 95-35\% MeOH; 34-35 min, 35\% MeOH. ESI-MS/MS detection of fusarin $\mathrm{C}$ eluting from the column was accomplished by monitoring three characteristic fragment ions $(\mathrm{m} / \mathrm{z}$ $364,382,396)$ of the $m / z 432[\mathrm{M}+\mathrm{H}]^{+}$ion of fusarin $\mathrm{C}$ in multiple reaction monitoring (MRM) mode. Quantitation of the fusarin $\mathrm{C}$ was done on the basis of the integrated intensity of the $\mathrm{m} / \mathrm{z}$ 364 fragment compared to a calibration curve generated from fusarin C standard solutions. Signal for LC-MS/MS determination of fusarin C may contain a contribution from products of the decomposition of fusarin C during conduct of the LC-MS/ MS analysis (Kleigrewe et al., 2012).

Fusaric acid was extracted from cracked maize cultures with $12 \mathrm{~mL}$ of acetonitrile/water $(50 \% \mathrm{v} / \mathrm{v})$ acidified to $\mathrm{pH} 2$ with $\mathrm{HCl}$ and analyzed by LC-MS/MS. Fusaric acid extract analysis was accomplished by use of a LC-MS/MS procedure developed for this study with the apparatus described above. Direct infusion $(50 \mu \mathrm{l} / \mathrm{min}, 1 \mathrm{mg} / \mathrm{mL}$ fusaric acid (Sigma Chemical Co., St. Louis, MO, USA) in 1:1 water/methanol with $5 \%$ acetic acid) ESI-MS/MS analysis of fusaric acid produced a spectrum with dominant fragments of $\mathrm{m} / \mathrm{z} 152$ and 162 . These dominant fragments were chosen for monitoring in LC-MS/MS experiments. HPLC solvents contained $0.3 \%$ trifluoroacetic acid as an ion pairing reagent. The HPLC gradient program $(300 \mu \mathrm{l} / \mathrm{min}$ gradient flow) consisted of the following steps: $0-10 \mathrm{~min}, 15 \% \mathrm{MeOH}$; 10-25 min, 15-90\% MeOH; 25-26 min, 90\% MeOH; 26-34 min, 90-15\% $\mathrm{MeOH}$; 34-35 min, 15\% MeOH. ESI-MS/MS detection of the fusaric acid ion eluting from the column was accomplished by monitoring the two fragment ions $(\mathrm{m} / \mathrm{z} 152$ and 162) and the parent ion $m / z 180[\mathrm{M}+\mathrm{H}]^{+}$ion. Quantitation of the fusaric acid was done on the basis of the integrated intensity of the $\mathrm{m} / \mathrm{z} 162$ fragment compared to that obtained from a calibration curve generated by analysis of fusaric acid concentration standards. Calibration curves generated for the LC-MS/MS analysis were linear over a range corresponding to $0.5-50 \mu \mathrm{g}$ fusaric acid per gram cracked maize. 


\section{Results}

3.1. Identification of clusters of co-expressed genes via microarray analysis

To identify SM biosynthetic gene clusters, we examined microarray data from wild-type $F$. verticillioides grown in liquid GYAM medium for 24, 48, 72 and $96 \mathrm{~h}$. We focused the search for clusters by looking for patterns of co-expression of genes located within $50-80 \mathrm{~kb}$ of the 16 PKS genes previously identified in the $F$. verticillioides genome sequence (Kroken et al., 2003; Ma et al., 2010). Genes were considered members of a cluster if (1) they were adjacent to each other, (2) a majority were expressed to a similar degree and (3) they shared a similar pattern of expression. Some consideration was given for inclusion of a predicted gene in a putative cluster based on similarity to previously characterized SM genes. The analysis revealed the presence of five such clusters. Although genes within each cluster exhibited similar patterns of expression, the patterns were not the same between clusters. Two clusters correspond to the previously characterized BIK (FVEG_03379-FVEG_03384) and FUM (FVEG_00315-FVEG_00329) clusters (Fig. 1) (Brown et al., 2008; Proctor et al., 2003). Expression of most of the fourteen FUM cluster genes was readily observed at
$48 \mathrm{~h}$ after which expression increased significantly through $96 \mathrm{~h}$ to a similar degree (Fig. 1A). In contrast, expression of three of the six $B I K$ cluster genes increased steadily through the course of the experiment while the other three were only detected at $96 \mathrm{~h}$ (Fig. 1B). Genes flanking the clusters exhibited patterns of expression that were markedly different from those of genes within the clusters (Fig. 1A and B). Confirmation of co-expression of genes within the BIK and FUM clusters via microarray analysis in $F$. verticillioides indicates that the same approach may be useful for identification of novel SM biosynthetic gene clusters that include PKS genes.

Co-expression of genes in the three other regions with a PKS gene has not been described previously. The first of these regions included the PKS gene FVEG_11086, several homologs of which are required for production of fusarin mycotoxins in other fusaria (Gaffoor et al., 2005; Song et al., 2004). Within this region FVEG_11086 and FVEG_11078-FVEG_11085 exhibited significant expression at all four time points (Fig. 2A). In contrast, genes (e.g. FVEG_11071-FVEG_11077 and FVEG_11087FVEG_11094) that flanked this region exhibited different patterns of expression. The second region included the previously characterized PKS gene PGL1 (FVEG_03695), which is required for production of the violet perithecial pigment. Within this

\section{(A) Fumonisin (FUM)}

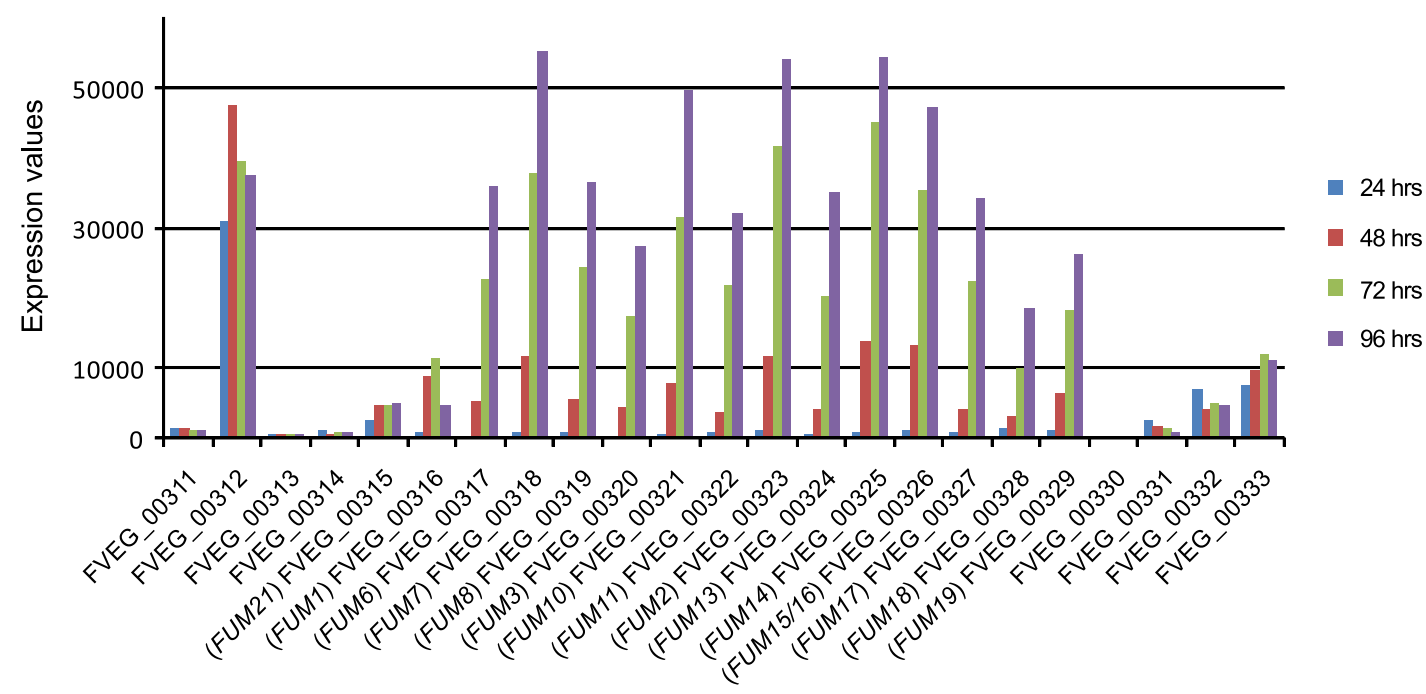

(B) Bikaverin (BIK)

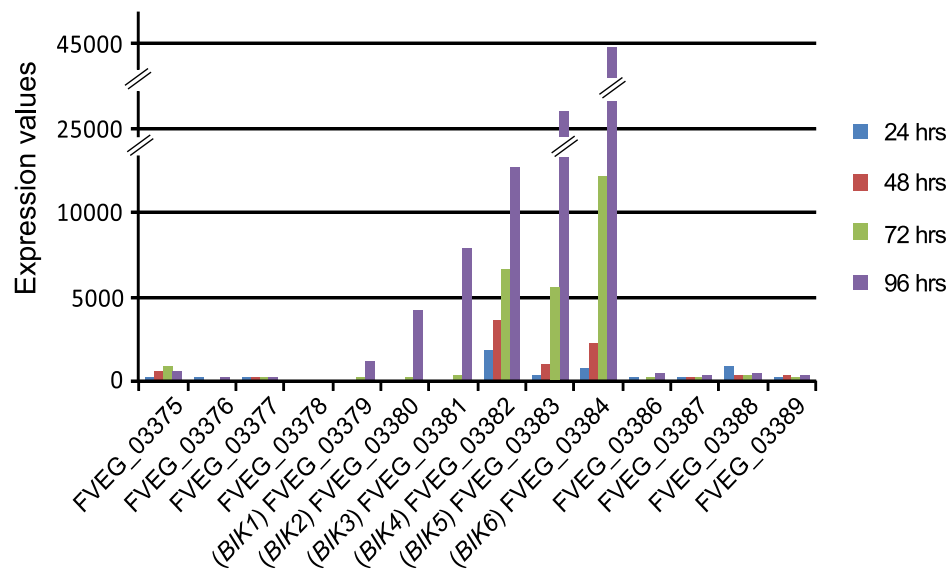

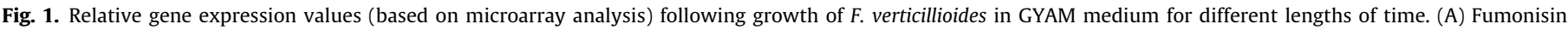
(FUM) gene cluster (B) Bikaverin (BIK) gene cluster. 


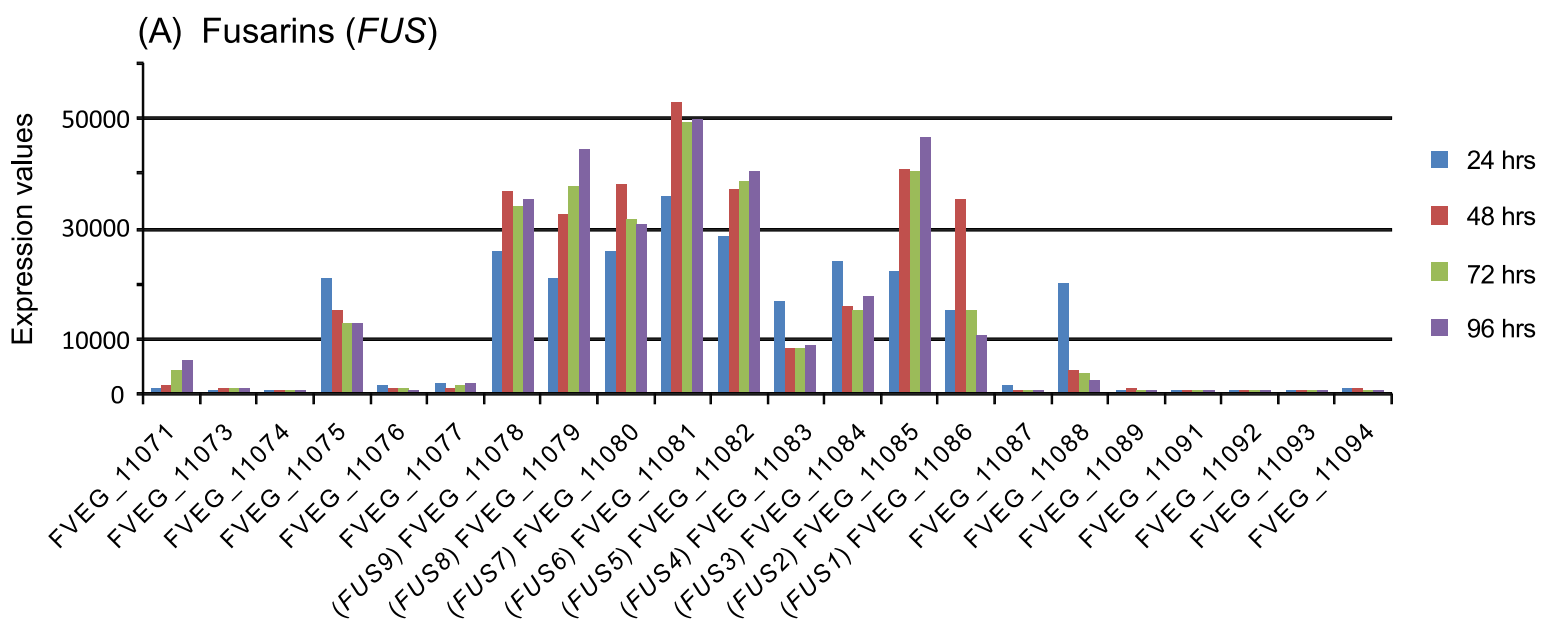

(B) Perithecium pigment $(P G L)$

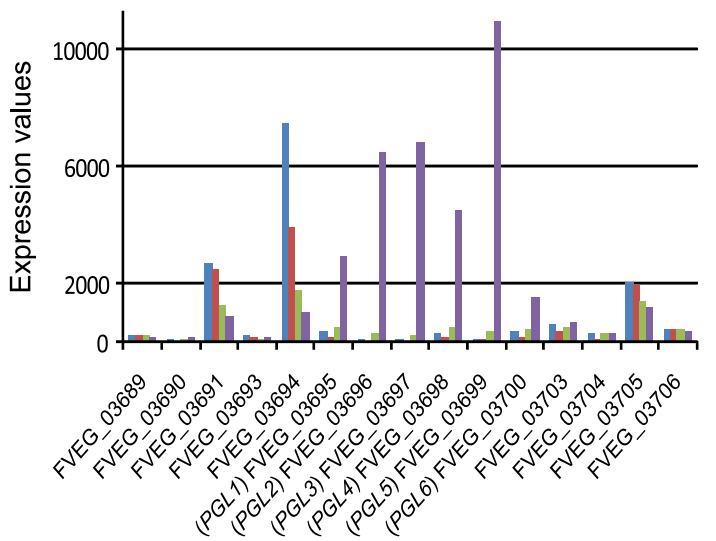

(C) Fusaric acid (FUB)
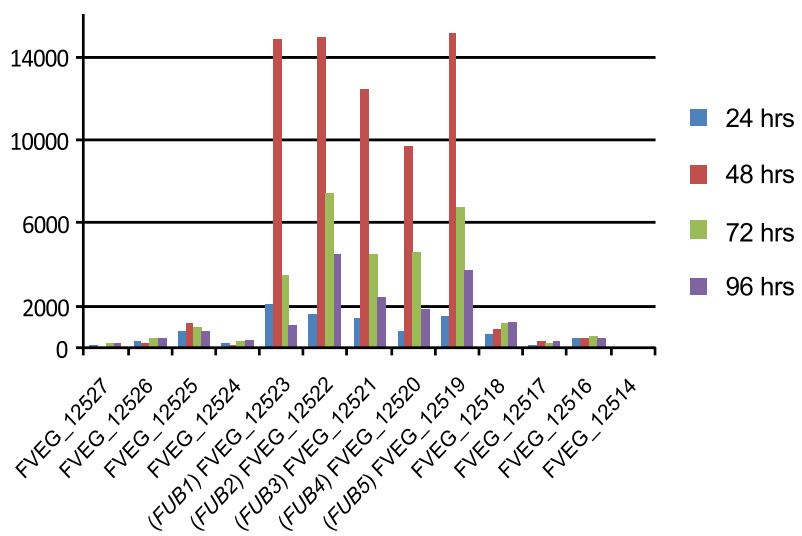

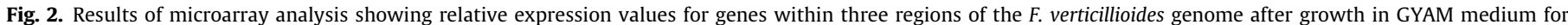

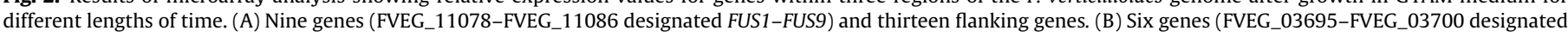
PGL1-PGL6) and nine flanking genes. (C) Five genes (FVEG_12519-FVEG_12524 designated FUB1-FUB5) and eight flanking genes.

region, PGL1 and genes FVEG_03696-FVEG_03700 did not exhibit significant expression until the 96-h time point (Fig. 2B). In contrast, genes flanking this region exhibited different patterns of expression. The third region included the uncharacterized PKS gene FVEG_12523. In this case, genes FVEG_12519-FVEG_12523 exhibited low levels of expression at $24 \mathrm{~h}$, higher at $48 \mathrm{~h}$, and then decreasing levels at 72 and $96 \mathrm{~h}$ (Fig. 2C). Again, genes flanking this region tended to exhibit different patterns of expression.

\subsection{Gene models and predicted functions of co-expressed genes}

The gene models for the nine co-expressed genes FVEG_11078-FVEG_11086 are supported by 406 Expressed Sequence Tags (ESTs) representing 336 different transcripts from the $F$. verticillioides Gene Index. The transcripts define 14 introns that have typical fungal GT/AG borders, including an atypically long, 546-bp intron in FVEG_11086, which was previously reported in the Fusarium moniliforme FVEG_1186 homolog fusA (Song et al. 2004). Excluding this intron, the average intron length is $53( \pm 7.2)$ bp. The predicted function of each gene, based on BLAST analysis is listed in Table 2. The gene models for the five co-expressed genes FVEG_12519-FVEG_12523 are supported by 44 ESTs representing 32 different transcripts. The transcripts define 10 of the 12 introns in the Broad gene models.
All 12 introns have typical fungal GT/AG borders and an average length of $52( \pm 5.6)$ bp. The predicted function of each gene, based on BLAST analysis is listed in Table 3.

\subsection{Northern analysis of FVEG_11086 and flanking genes}

Expression of genes within a 55-kb region that included PKS gene FVEG_11086 was examined by Northern blot analysis of RNA prepared from GYAM cultures of wild-type $F$. verticillioides harvested at 12, 24, 48, 72 and $96 \mathrm{~h}$ of growth (Fig. 3). Although we were not able to detect a full-length FVEG_11086 transcript, estimated to be around $12 \mathrm{~kb}$, we did observe significant hybridization signal between 1 and $3 \mathrm{~kb}$ at 24, 48, 72 and $96 \mathrm{~h}$. The failure to detect a full-length transcript may be due to poor transfer of large RNAs onto the membrane while the detection of multiple, small RNAs may be due to the random mechanical breakage of large transcripts during the RNA extraction protocol (Diez et al., 1990). In contrast, bands of the expected sizes were observed for genes FVEG_11078-FVEG_11085 immediately upstream of FVEG_11086 as well as for FVEG_01187. Each gene exhibited little or no expression at $12 \mathrm{~h}$ but moderate to high levels of expression at $24 \mathrm{~h}$ that tended to decline after $72 \mathrm{~h}$. In contrast, a majority of the genes in the region flanking FVEG_11078-FVEG_11087 tended to exhibit different patterns of expression (Fig. 3). Thus, in Northern analysis genes FVEG_11078-FVEG_11086 exhibited similar 


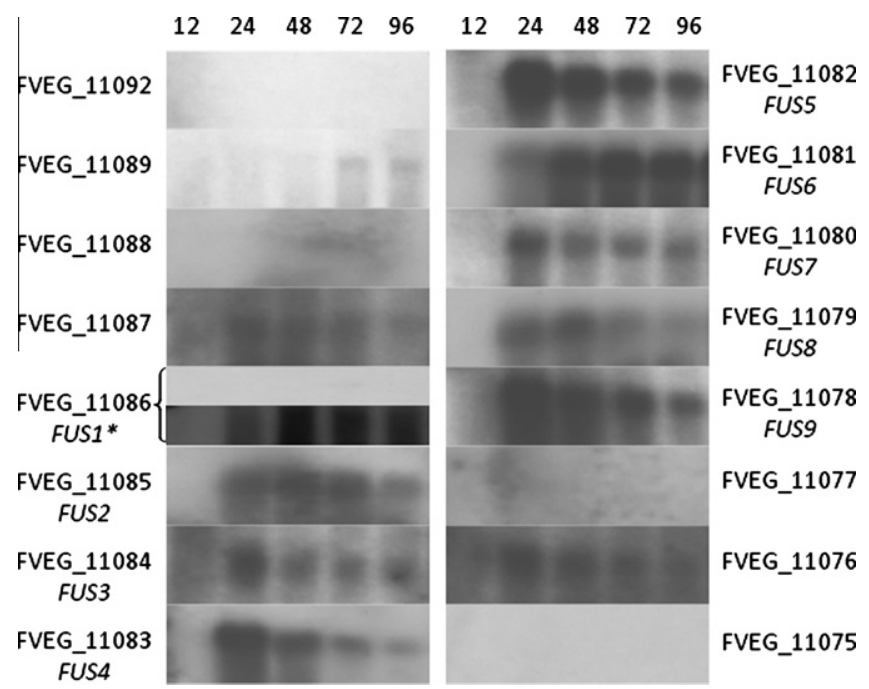

Fig. 3. Northern analysis of FUS gene cluster (FVEG_11078-FVEG_11086) and selected flanking genes after growth on GYAM medium. *The Northern analysis of FVEG_11086 is displayed in two sections. The top section is the portion of the blot corresponding to $\sim 12 \mathrm{~kb}$, the size expected for the FVEG_11086 transcript. The lower section is around $3 \mathrm{~kb}$ and includes a portion of the multiple hybridization signals observed.

patterns of expression when $F$. verticillioides was grown in GYAM medium.

3.4. Functional analysis of PKS genes FVEG_11086 and FVEG_12523 for fusarin $C$ and fusaric acid biosynthesis

LC-MS/MS analysis of 10-day-old cracked maize culture extracts of hygromycin-resistant isolates recovered following transformation of wild-type $F$. verticillioides with the FVEG_11086 disruption vector (pPKS10 $\Delta / \mathrm{Hyg}$ ) indicated that two transformants, designated GmT606 and GmT644, did not produce detectable levels of fusarin C (Fig. 4). In contrast, the wild-type progenitor strain and transformants in which pPKS10 $\Delta /$ Hyg integrated ectopically (e.g. strain GmT601) produced 150-297 $\mu$ g fusarin $C$ per gram of cracked maize medium. PCR analysis indicated GmT644 carried a disrupted FVEG_11086 (Supplemental Fig. 1). Disruption of FVEG_11086 in GmT644 was confirmed by Southern blot analysis (data note shown). LC-MS/MS analysis of 10-day-old cracked maize culture extracts of hygromycin-resistant isolates recovered following transformation of wild-type $F$. verticillioides with the FVEG_12523 deletion amplicons indicated that two, designated $\mathrm{GmTcm} 1$ and $\mathrm{GmTcm} 5$, did not produce detectable levels of fusaric acid whereas a similar analysis of the wild-type progenitor indicated that it produced $18.4 \mu \mathrm{g}$ fusaric acid per gram of cracked maize medium (Fig. 5). PCR analysis indicated that both $\mathrm{GmTcm} 1$ and $\mathrm{GmTcm} 5$ lacked half of the FVEG_12523 coding sequence (Supplemental Fig. 2). All four transformants exhibited wild-type growth and conidiation on a variety of growth media.

\subsection{Comparative genomic analysis}

Examination of available Fusarium genomic sequences revealed regions homologous to FVEG_11078-FVEG_11086 in F. graminearum and F. solani (Fig. 6, Table 3). F. graminearum has homologs of all nine $F$. verticillioides genes. The homologous genes share $78 \%$ deduced amino acid identity on average and are organized in the same order and orientation in the $F$. graminearum and $F$. verticillioides genomes. F. solani has homologs of eight of the nine
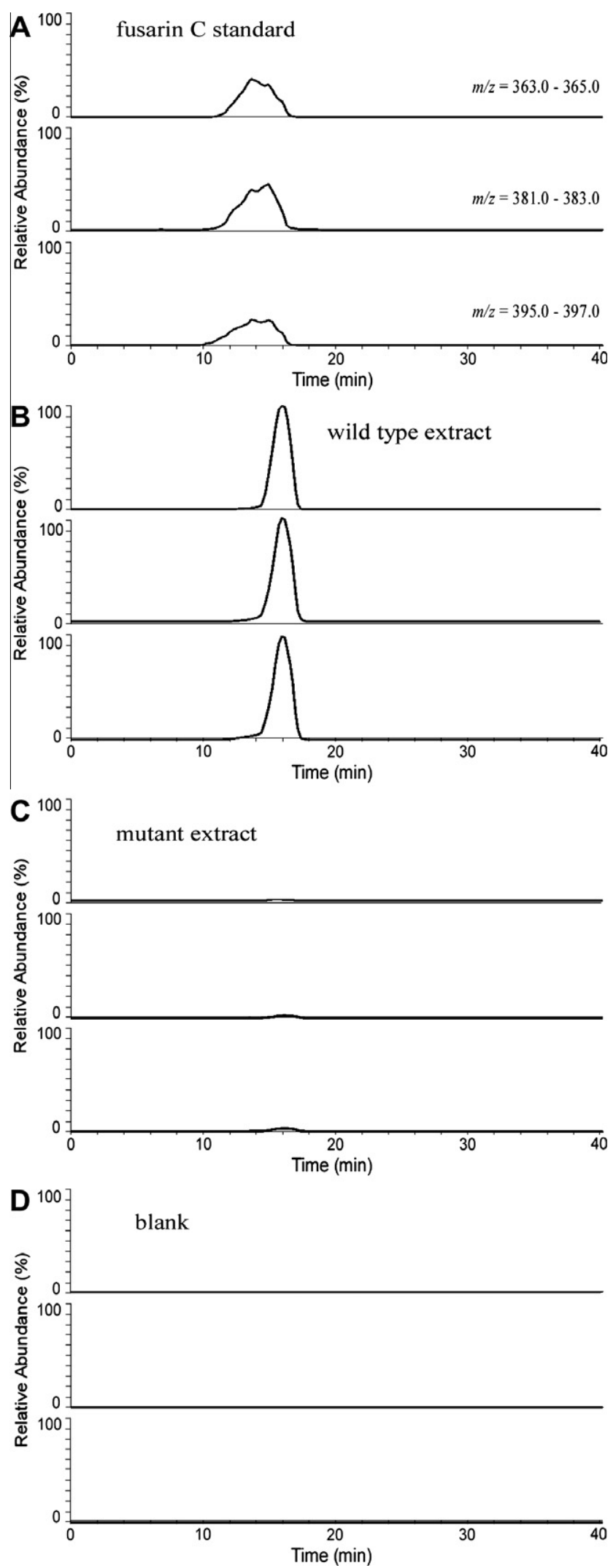

Fig. 4. Reconstructed LC-MS/MS (MRM) chromatograms for (A) a fusarin C standard $(0.1 \mathrm{mg} / \mathrm{mL}), 10$ day culture extracts of (B) NRRL 13447 and (C) GmT606 ( $\Delta$ FUS1), and (D) a blank. The first panel in each set is the fragment ion mass range $\mathrm{m} / \mathrm{z}$ $363.0-365.0$, second panel is the fragment ion mass range $m / z 381.0-383.0$ and the third panel is the fragment ion mass range $m / z$ 395.0-397.0 of fusarin $C$. The fusarin C parent ion is $432[\mathrm{M}+\mathrm{H}]^{+}$. The relative abundance has been normalized to the wild-type strain. 


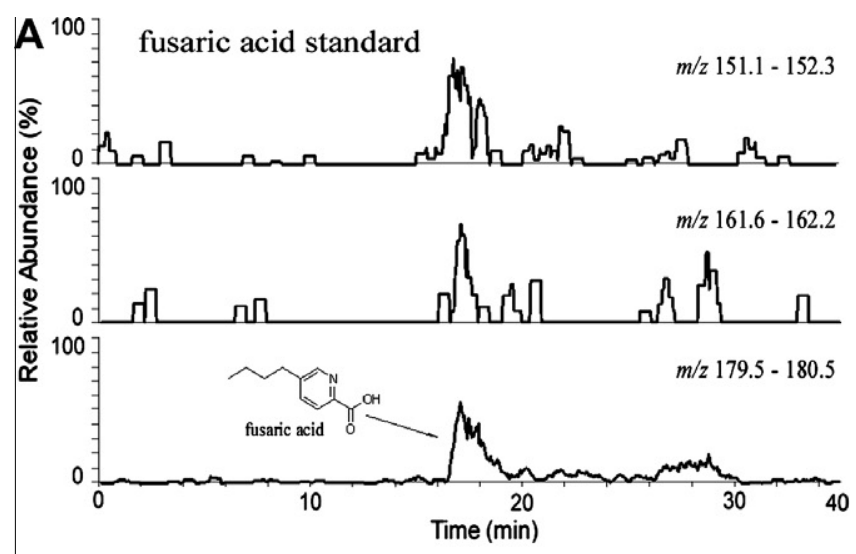

F. verticillioides genes; a homolog of FVEG_11082 is not present in $F$. solani. In addition, the homologous genes in $F$. verticillioides and $F$. solani share $68 \%$ deduced amino acid identity on average and exhibit marked differences in arrangement in the two genomes (Fig. 6, Table 4). Intergenic regions between homologous pairs of genes in all three fungi are of similar length (Fig. 6). The genes on either side of each gene cluster in each Fusarium do not share any similarity indicating that the genomic locations of each cluster are different (Fig. 6).
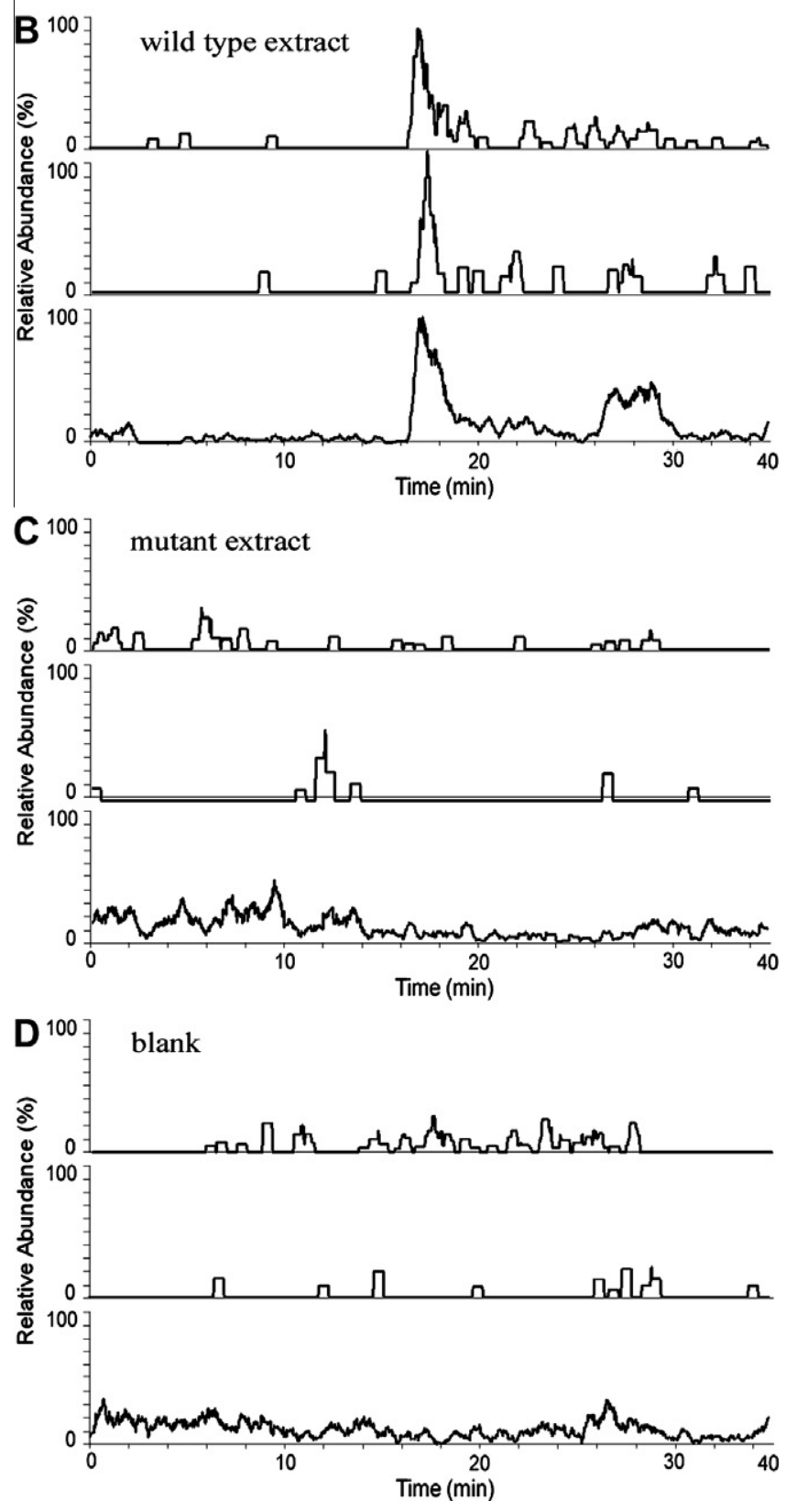

Fig. 5. Reconstructed LC-MS/MS (MRM) chromatograms for (A) a fusaric acid standard, 10 day culture extracts of (B) NRRL 13447 and (C) GmTcm1 ( $\triangle$ FUB1), and (D) a blank. The first panel in each set is the fragment ion mass range $m / z 151.1-$ 152.3 while second panel in each set is the fragment ion mass range $\mathrm{m} / \mathrm{z} 161.6$ 162.2 . The third panel is the parent ion with a mass range of $m / z 179.5-180.5$. The relative abundance has been normalized to the wild type strain.

\section{Discussion}

Two hallmarks of genes involved in synthesis of a fungal SM are their co-expression and their clustering within a genome (Keller et al., 2005). Previous Northern and EST analyses established coexpression and clustering of fumonisin biosynthetic (FUM) genes in F. verticillioides (Brown et al., 2007; Proctor et al., 2003) and bikaverin biosynthetic (BIK) genes in F. fujikuroi (Wiemann et al., 2009). Functional analyses confirmed the roles of most genes within these clusters in the synthesis of fumonisins and bikaverin respectively. In the current study, analysis of microarray data from $F$. verticillioides grown in GYAM medium confirmed co-expression of genes within the FUM and BIK clusters (Fig. 1A and B) and indicated that it should be possible to use microarray data to identify additional SM biosynthetic gene clusters. Thus, co-expression of the three PKS genes (PGL1, FVEG_11086 and FVEG_12523) with their respective flanking genes provides evidence for three additional SM biosynthetic gene clusters. Furthermore, functional analyses of the PKS genes, done previously (Gaffoor et al., 2005; Proctor et al., 2007; Song et al., 2004) and during the course of the current study, link each of these clusters of co-expressed genes with production of an SM.

$P G L 1$ homologs in $F$. verticillioides and $F$. graminearum were previously shown to be required for production of a violet perithecial pigment (Gaffoor et al., 2005; Proctor et al., 2007), a trait that can be used to distinguish between fusaria with a Gibberella teleomorph from those with a Nectria teleomorph. Co-expression of PGL1 and the adjacent genes FVEG_03696-FVEG_03700 suggests that these six genes constitute a gene cluster that is responsible for synthesis of the perithecial pigment. Based on this and for consistency with the PGL1 designation for the PKS gene, we propose that FVEG_03696-FVEG_03700 be designated PGL2-PGL6 (Fig. 2B).

Initial evidence for the PGL gene cluster came from a study describing the conservation in position and orientation of the two genes immediately upstream of PGL1 in F. verticillioides, F. graminearum and $F$. solani. The two genes are predicted to encode activities consistent with SM synthesis (Proctor et al., 2007). However, six additional genes upstream of PGL1 are conserved in $F$. verticillioides, $F$. graminearum, and $F$. oxysporum but not $F$. solani. The most likely consequence of the lack of conservation of genes flanking PGL1 in F. solani and F. verticillioides is production of different $\mathrm{SM}$ end products in the two fungi. As noted above, $F$. verticillioides PGL1 is responsible for the synthesis of a violet pigment that accumulates in the walls of perithecia of some Fusarium/Gibberella species (Gaffoor et al., 2005; Proctor et al., 2007). In contrast, the pigment that accumulates in the perithecia of $F$. solani is red and results from the activity of a different PKS (encoded by $p k s N$; JGI_101778) (Graziani et al., 2004). Although the SM end product of the F. solani PGL1 (JGI_33672) homolog is unknown, this fungus has been reported to produce fusarubin (Fig. 1) (Kurobane et al., 1980), a metabolite that is not produced by PGL1 mutants but is produced by wild-type $F$. verticillioides (M. Busman and R.H. Proctor, unpublished). PGL1 is predicted to encode an non-reducing PKS (NR-PKS) which is consistent with the synthesis of the aromatic structure of fusarubin. Studies are in progress to determine 


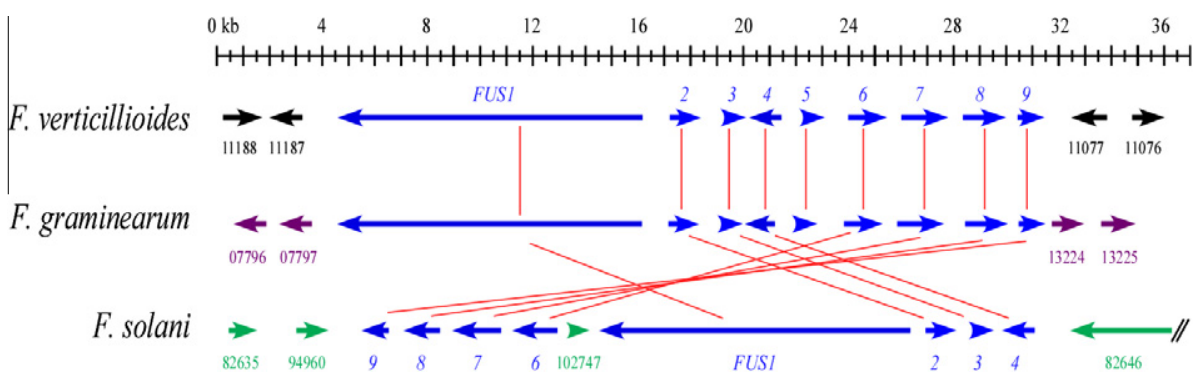

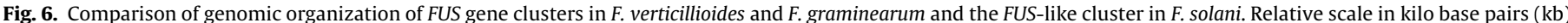

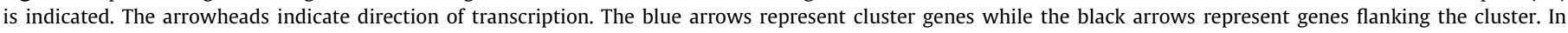

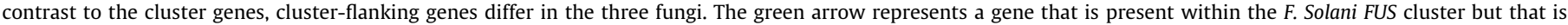
absent in the cluster in the other two fungi. The numbers underneath the black arrows refer to database gene designations for each fungus respectively.

Table 4

Comparison of Fusarium FUS homologs.

\begin{tabular}{|c|c|c|c|c|c|c|c|c|}
\hline Gene name & Fv $(\text { FVEG_\# })^{\mathrm{a}}$ & Protein (AAs) & Fg (FGSG_\#) & Protein (AAs) & $\mathrm{Fg} \%$ to $\mathrm{Fv}^{2}$ & Nh (JGI_\#) & Protein (AAs) & Nh\% to Fv \\
\hline FUS9 & 11,078 & 355 & 07805 & 327 & 67.3 & 101,086 & 361 & 59.4 \\
\hline FUS8 & 11,079 & 514 & 07804 & 515 & 84.6 & 45,012 & 509 & 71.2 \\
\hline FUS7 & 11,080 & 461 & 07803 & 465 & 75.9 & 45,085 & 466 & 65.9 \\
\hline FUS6 & 11,081 & 563 & 07802 & 561 & 89.7 & 45,233 & 544 & 80.9 \\
\hline FUS5 & 11,082 & 233 & 07801 & 233 & 75.1 & - & NA & NA \\
\hline FUS4 & 11,083 & 439 & 07800 & 437 & 74.8 & 82,635 & 439 & 59.8 \\
\hline FUS3 & 11,084 & 220 & 13,223 & 220 & 74.3 & 62,410 & 219 & 69.1 \\
\hline FUS2 & 11,085 & 419 & 13,222 & 419 & 88.0 & 104,901 & 420 & 75.8 \\
\hline FUS1 & 11,086 & 3734 & 07798 & 3738 & 71.8 & 70,660 & 3742 & 64.3 \\
\hline
\end{tabular}

a Designations for the FUS genes at the Fusarium Comparative Database at the Broad Institute for F. verticillioides (Fv) and F. graminearum (Fg) and the JGI website for N. haematococca $(\mathrm{Nh})$.

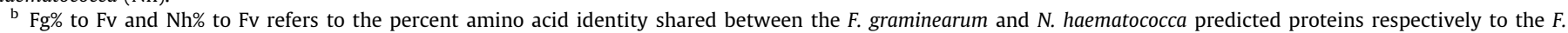
verticillioides homologous proteins.

the relationship between fusarubin and the perithecial pigment. Fusarubin may be a monomer or building block of the perithecial pigment, which after polymerization or attachment to the perithecial wall, is recalcitrant to analysis due to its complex nature. It should be noted that the putative $F$. graminearum PGL cluster includes a gene, FGSG_09185 that is not present in the $F$. verticillioides PGL cluster. FGSG_09185 is located between the homologs of PGL3 and PGL4. The most closely related FGSG_09185 homolog in F. verticillioides is FVEG_13758 (E value $=0.0$ ), and it is located on a different chromosome. Recently, a homolog of the PGL cluster was identified in F. fujikuroi (Studt et al., 2012). Functional analysis of genes in the cluster demonstrated that the F. fujikuroi homologs of PGL1, PGL2 and PGL3 are required for production of fusarubins and that the PGL1 homolog is required for perithecial pigmentation (Studt et al., 2012). Although the functional characterization of most of the cluster in F. fujikuroi provides strong evidence that fusarubins, which are red, are precursors of the perithecial pigment, which is violet, the structure of the perithecial pigment has yet to be determined.

Previously, putative homologs of FVEG_11086 were shown by gene inactivation analysis to be required for fusarin production in F. graminearum (FUS1) (Gaffoor et al., 2005), F. moniliforme (fusA) and $F$. venenatum (fusA) (Song et al., 2004). In addition, inactivation of a putative ortholog in Metarhizium robertisii (NGS1) blocked production of compound NG-391, which is structurally similar to fusarin C (Donzelli et al., 2010). Because F. moniliforme has been resolved into multiple morphologically similar species, including $F$. verticillioides, it is not clear whether the $F$. moniliforme strain examined by Song et al. was $F$. verticillioides or another species. Therefore, we inactivated $F$. verticillioides FUS1 homolog, FVEG_11086, in strain FRC M-3125 (FGSC 7600, NRRL 20956), a standard fumonisin-producing, pathogenic, and mating type tester strain as well as the strain used to determine the $F$. verticillioides genome sequence and to generate the genetic linkage map of the fungus. The analysis confirmed that FVEG_11086 is required for fusarin production in $F$. verticillioides and, therefore, is a functional homolog of FUS1/fusA. Thus, FVEG_11086 will be referred to hereafter as FUS1.

Additional evidence that the nine $F$. verticillioides FUS genes constitute a gene cluster is that contiguous groupings of FUS homologs in the $F$. graminearum and $F$. solani genomes and that flanking genes on either side of the putative FUS cluster differ in each species (Fig. 3 and Table 3). This break in synteny, where homologous biosynthetic genes in related fungi are clustered but the clusters are located in different genomic locations, may be a common attribute in filamentous fungi (Proctor et al., 2009). In summary, based on the requirement of FUS1 for fusarin production, the co-expression of FUS1 and FVEG_11078-FVEG_11085, and the conservation of the cluster in Fusarium, we propose that these nine genes constitute a fusarin biosynthetic gene cluster. For consistency with the FUS1 designation, we also propose that FVEG_11078-FVEG_11085 be designated FUS9-FUS2 as shown in Fig. 3.

To our knowledge, fusarin production has not been reported in F. solani. However, the presence of a putative FUS gene cluster suggests that it has the genetic potential to produce fusarins or a fusarin-like metabolite(s). In contrast, the $F$. oxysporum genome does not contain a FUS gene cluster and this species has not been reported to produce fusarins.

Co-expression of PKS gene FVEG_12523 with adjacent genes FVEG_12519-FVEG_12522 suggests that this region could also be a SM biosynthetic gene cluster. Based on the co-expression and on the lack of production of fusaric acid in the FVEG_12523 deletion mutants, we propose that FVEG_12519-FVEG_12523 constitute a fusaric acid biosynthetic gene cluster (Fig. 7). Furthermore, we propose that the genes be designated as $F U B$, for fusaric acid biosynthetic genes. The PKS gene FVEG_12523 will be referred to 


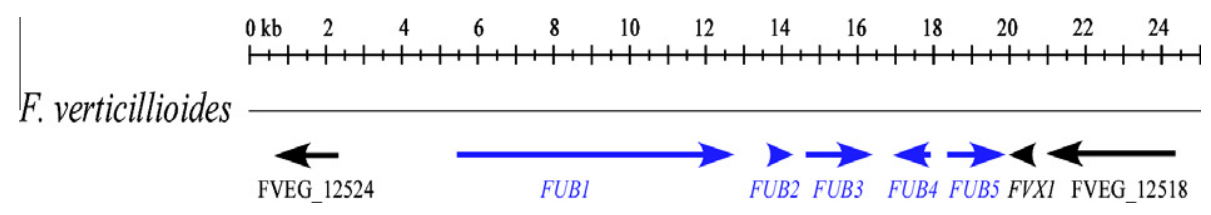

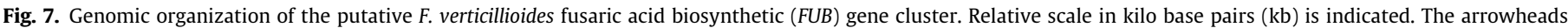

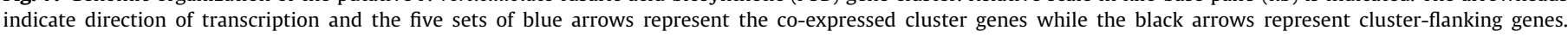

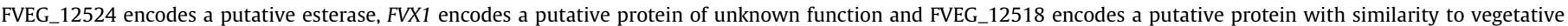
incompatibility proteins or beta transducin-like proteins.

as FUB1 and FVEG_12519-FVEG_12522 be referred to as FUB5FUB2, as shown in Fig. 2C.

No gene involved in fusaric acid biosynthesis has yet been reported in the literature. Precursor feeding studies indicate that fusaric acid biosynthesis requires three acetate units (a triketide via a PKS) and aspartate (Dobson et al., 1967; Stipanovic et al., 2011b). Based on the observation that two of three other Fusarium SMs derived from acetate and an amino acid, fusarin C (Song et al., 2004), and equisetin (Sims et al., 2005), are synthesized from a PKS with a non-ribosomal peptide synthase module (PKS-NRPS), we expected that the fusaric acid PKS to have a NRPS module as well. In other PKSs with an NRPS module, the module serves to activate a specific amino acid and covalently attach it to the carbon chain generated by the PKS. In contrast, the amino acid in the third Fusarium SM (fumonisins) is linked to the polyketide carbon chain via an $\alpha$-oxoamine synthase encoded by a gene, FUM8, in the FUM cluster (Proctor et al., 2008).

PKS-NRPS genes occur frequently in fungal genomes. In $F$. verticillioides, three PKSs include an NRPS module (Ma et al., 2010). Work in our laboratory demonstrated that two of these three were not involved in fusaric acid synthesis (R.H. Proctor and M. Busman, unpublished). The finding that the PKS gene FUB1 is required for fusaric acid synthesis but does not have an NRPS module and the putative fusaric acid biosynthetic gene cluster does not include an $\alpha$-oxoamine synthase gene indicates that fusaric acid synthesis involves a novel mechanism for the incorporation of an amino acid (or derivative). The function of the putative protein encoded by FUB3, an aspartokinase (i.e. amino acid kinase), its physical proximity to and co-expression with FUB1 strongly suggest that FUB3 is also involved in fusaric acid synthesis. Gene deletion studies are in progress to determine if this hypothesis is correct.

Based on the chemical structure of fusaric acid and previous published substrate feeding experiments (Dobson et al., 1967; Stipanovic et al., 2011b), we predict that the FUB1-encoded PKS (Fub1) catalyzes condensation of three acetate units to form a fully reduced 6 -carbon polyketide chain (Fig. 8). The proposed function of FUB3, FUB4 and FUB5 in fusaric acid synthesis is speculative (Table 3 and Fig. 8). FUB3, encoding a putative amino acid kinase, likely plays a critical role in assimilating a nitrogen from glutamine or oxaloacetate to form fusaric acid. FUB5 is predicted to encode an acetyltransferase, which suggests that it could be responsible for the addition of a methyl group to the carboxylic acid moiety of fusaric acid to yield methyl fusarate (Fig. 8, a metabolite that often occurs along with fusaric acid in Fusarium cultures (Amalfitano et al., 2002). FUB4 is predicted to encode a hydrolase. A role for the hydrolase in fusaric acid synthesis is still more speculative. Nevertheless, based on the observation that methyl fusarate is more toxic than fusaric acid (Stipanovic et al., 2011a), the putative hydrolase may catalyze conversion of methyl fusarate to the less toxic fusaric acid by removing the methyl group (Fig. 8). The ability to readily interconvert these two materials may allow Fusarium to more precisely control relative concentrations of fusaric acid and methyl fusarate in order to mitigate their impact on host plants, bacteria, or other fungi. We are in the process of determining whether FUB4 is involved in the proposed conversion of methyl

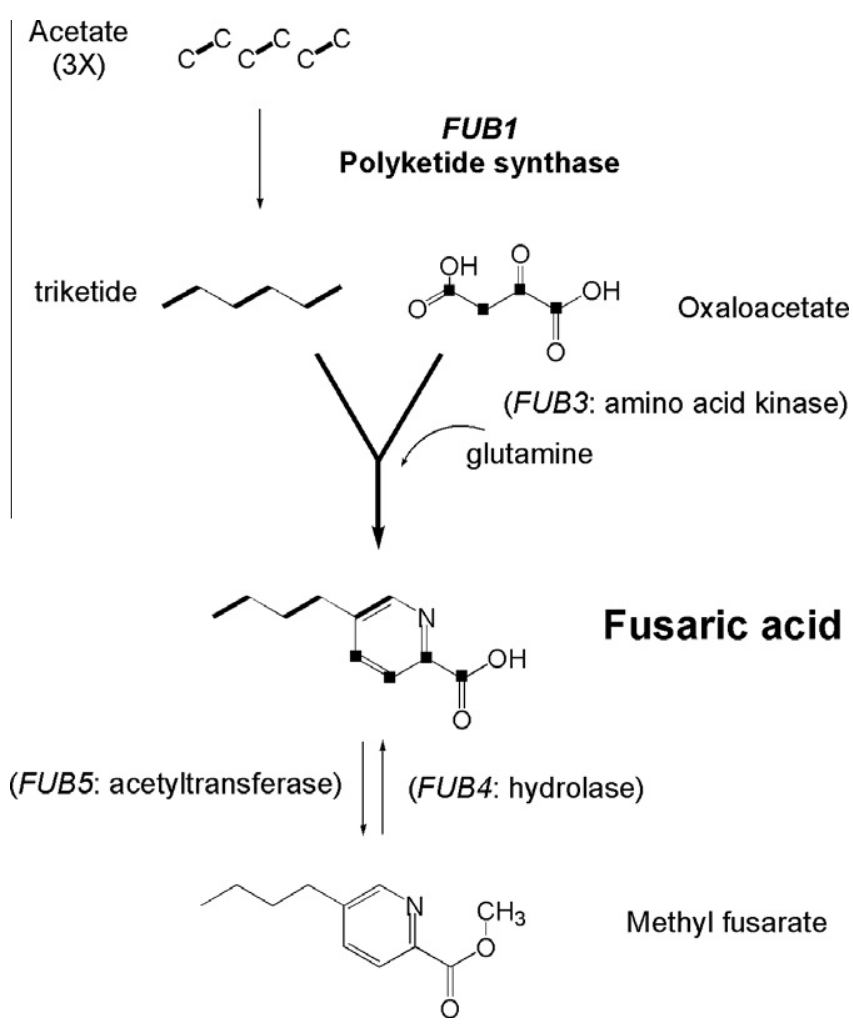

Fig. 8. A proposed biochemical pathway for fusaric acid biosynthesis in $F$. verticillioides. The assignment of FUB1 is based on functional studies and the assigned roles for FUB3, FUB4 and FUB5 (in parenthesis) were based on BLAST analysis and biochemical considerations.

fusarate to fusaric acid and whether it serves a protective role in planta against the more harmful effects of methyl fusarate. In addition, the identification and inactivation of fusaric acid biosynthetic genes will allow rigorous examination of the role of fusaric acid in plant and mammalian diseases.

In early studies, researchers demonstrated the utility of microarray analysis for identifying SM biosynthetic gene clusters with mutant strains of Aspergillus in which production of the global regulatory protein LaeA was over expressed or was blocked by gene deletion (Bok et al., 2006; Bok and Keller, 2004). Gene clusters were identified by changes in expression in the mutants relative to the wild type. In the current study, microarray analysis of wild-type $F$. verticillioides confirmed co-expression of genes within the previously characterized FUM and BIK clusters and provided support for microarray-based identification of the PGL, FUS and FUB clusters by gene co-expression. The failure to observe expression of the 11 other PKSs under these conditions was not unexpected because 18 different culture conditions were required to observe expression of 14 of the $15 \mathrm{~F}$. graminearum PKS genes. (Gaffoor et al., 2005). Additional evidence for the PGL cluster consists of the presence of cluster homologs in $F$. verticillioides, 
F. oxysporum, and F. graminearum, whereas additional evidence for the FUS cluster consists of the presence of cluster homologs in $F$. verticillioides, $F$. graminearum and $F$. solani as well as Northern blot data showing co-expression of FUS genes in F. verticillioides. Thus, our results support the concept that SM biosynthetic gene clusters can be identified by whole genome-based microarray analysis of Fusarium grown in different conditions. Functional analysis by mutagenesis of all individual putative cluster genes is required to verify involvement and provide evidence for their roles in synthesis of the corresponding SMs. In the current study, we exploited differences in gene expression that occur over time in a semidefined liquid medium that was designed to promote fumonisin production in $F$. verticillioides but also supports production of other secondary metabolites in the fungus. In future studies, wholegenome expression analysis of Fusarium grown under other culture conditions may provide evidence for additional SM biosynthetic gene clusters in this agriculturally important genus of filamentous fungi.

\section{Acknowledgments}

We would like to thank Chris McGovern, Crystal Probyn and Marcie Moore for technical assistance. Mention of trade names or commercial products in this article is solely for the purpose of providing specific information and does not imply recommendation or endorsement by the US Department of Agriculture. USDA is an equal opportunity provider and employer.

\section{Appendix A. Supplementary material}

Supplementary data associated with this article can be found, in the online version, at http://dx.doi.org/10.1016/j.fgb.2012.05.010.

\section{References}

Alexander, N.J., Hohn, T.M., McCormick, S.P., 1998. The TRI11 gene of Fusarium sporotrichioides encodes a cytochrome P-450 monooxygenase required for C-15 hydroxylation in trichothecene biosynthesis. Appl. Environ. Microbiol. 64, 221225.

Altschul, S.F., Madden, T.L., Schaffer, A.A., Zhang, J., Zhang, Z., Miller, W., Lipman, D.J., 1997. Gapped BLAST and PSI-BLAST: a new generation of protein database search programs. Nucleic Acids Res. 25, 3389-3402.

Amalfitano, C., Pengue, R., Andolfi, A., Vurro, M., Zonno, M.C., Evidente, A., 2002. HPLC analysis of fusaric acid, 9,10-dehydrofusaric acid and their methyl esters, toxic metabolites from weed pathogenic Fusarium species. Phytochem. Anal. 13, 277-282.

Bacon, C.W., Porter, J.K., Norred, W.P., Leslie, J.F., 1996. Production of fusaric acid by Fusarium species. Appl. Environ. Microbiol. 62, 4039-4043.

Bok, J.W., Chiang, Y.M., Szewczyk, E., Reyes-Dominguez, Y., Davidson, A.D., Sanchez, J.F., Lo, H.C., Watanabe, K., Strauss, J., Oakley, B.R., Wang, C.C., Keller, N.P., 2009. Chromatin-level regulation of biosynthetic gene clusters. Nat. Chem. Biol. 5, 462-464.

Bok, J.W., Hoffmeister, D., Maggio-Hall, L.A., Murillo, R., Glasner, J.D., Keller, N.P., 2006. Genomic mining for Aspergillus natural products. Chem. Biol. 13, 31-37.

Bok, J.W., Keller, N.P., 2004. LaeA, a regulator of secondary metabolism in Aspergillus spp. Eukaryot. Cell. 3, 527-535.

Bolstad, B.M., Irizarry, R.A., Astrand, M., Speed, T.P., 2003. A comparison of normalization methods for high density oligonucleotide array data based on variance and bias. Bioinformatics 19, 185-193.

Brown, D.W., Butchko, R.A., Busman, M., Proctor, R.H., 2007. The Fusarium verticillioides FUM gene cluster encodes a $\mathrm{Zn}(\mathrm{II}) 2$ Cys 6 protein that affects FUM gene expression and fumonisin production. Eukaryot. Cell 6, 1210-1218.

Brown, D.W., Butchko, R.A., Proctor, R.H., 2008. Genomic analysis of Fusarium verticillioides. Food Addit. Contam. 25, 1158-1165.

Brown, D.W., Cheung, F., Proctor, R.H., Butchko, R.A., Zheng, L., Lee, Y., Utterback, T., Smith, S., Feldblyum, T., Glenn, A.E., Plattner, R.D., Kendra, D.F., Town, C.D., Whitelaw, C.A., 2005. Comparative analysis of 87,000 expressed sequence tags from the fumonisin-producing fungus Fusarium verticillioides. Fungal Genet. Biol. 42, 848-861.

Brown, D.W., McCormick, S.P., Alexander, N.J., Proctor, R.H., Desjardins, A.E., 2002. Inactivation of a cytochrome P-450 is a determinant of trichothecene diversity in Fusarium species. Fungal Genet. Biol. 36, 224-233.

Butchko, R.A., Plattner, R.D., Proctor, R.H., 2003. FUM9 is required for C-5 hydroxylation of fumonisins and complements the meitotically defined Fum 3 locus in Gibberella moniliformis. Appl. Environ. Microbiol. 69, 6935-6937.
Capasso, R., Evidente, A., Cutignano, A., Vurro, M., Zonno, M.C., Bottalico, A., 1996. Fusaric and 9,10-dehydrofusaric acids and their methyl esters from Fusarium nygamai. Phytochemistry 41, 1035-1039.

Catlett, N.L., Lee, B.N., Yoder, O.C., Turgeon, B.G., 2002. Split-marker recombination for efficient targeted deletion of fungal genes. Fun. Genet. News. 49, 9-11.

Chiang, Y.M., Szewczyk, E., Davidson, A.D., Keller, N., Oakley, B.R., Wang, C.C., 2009. A gene cluster containing two fungal polyketide synthases encodes the biosynthetic pathway for a polyketide, asperfuranone, in Aspergillus nidulans. J. Am. Chem. Soc. 131, 2965-2970.

Desjardins, A.E., Busman, M., Muhitch, M., Proctor, R.H., 2007. Complementary host-pathogen genetic analyses of the role of fumonisins in the Zea maysGibberella moniliformis interaction. Phys. Mol. Plant Path. 70, 149-160.

Desjardins, A.E., Munkvold, G.P., Plattner, R.D., Proctor, R.H., 2002. FUM1-a gene required for fumonisin biosynthesis but not for maize ear rot and ear infection by Gibberella moniliformis in field tests. Mol. Plant Microbe. Interact. 15, 11571164.

Desjardins, A.E., Proctor, R.H., 2001. Biochemistry and genetics of Fusarium toxins. In: Summerell, B.A. (Ed.), Fusarium: Paul E. Nelson Memorial Symposium. APS Press, St. Paul, pp. 50-69.

Desjardins, A.E., Proctor, R.H., 2007. Molecular biology of Fusarium mycotoxins. Int. J. Food Microbiol. 119, 47-50.

Diez, B., Gutierrez, S., Barredo, J.L., van Solingen, P., van der Voort, L.H., Martin, J.F., 1990. The cluster of penicillin biosynthetic genes. Identification and characterization of the $p c b A B$ gene encoding the alpha-aminoadipyl-cysteinylvaline synthetase and linkage to the $p c b C$ and penDE genes. J. Biol. Chem. 265, 16358-16365.

Dobson, T.A., Desaty, D., Brewer, D., Vining, L.C., 1967. Biosynthesis of fusaric acid in cultures of Fusarium oxysporum Schlecht. Can. J. Biochem. 45, 809-823.

Donzelli, B.G., Krasnoff, S.B., Churchill, A.C., Vandenberg, J.D., Gibson, D.M., 2010. Identification of a hybrid PKS-NRPS required for the biosynthesis of NG-391 in Metarhizium robertsii. Curr. Genet. 56, 151-162.

Frisvad, J.C., Smedsgaard, J., Samson, R.A., Larsen, T.O., Thrane, U., 2007. Fumonisin $\mathrm{B}_{2}$ production by Aspergillus niger. J. Agric. Food. Chem. 55, 9727-9732.

Gaffoor, I., Brown, D.W., Plattner, R., Proctor, R.H., Qi, W., Trail, F., 2005. Functional analysis of the polyketide synthase genes in the filamentous fungus Gibberella zeae (anamorph Fusarium graminearum). Eukaryot. Cell 4, 1926-1933.

Gelderblom, W.C., Thiel, P.G., Jaskiewicz, K., Marasas, W.F., 1986. Investigations on the carcinogenicity of fusarin C-a mutagenic metabolite of Fusarium moniliforme. Carcinogenesis 7, 1899-1901.

Gelderblom, W.C., Thiel, P.G., van der Merwe, K.J., Marasas, W.F., Spies, H.S., 1983. A mutagen produced by Fusarium moniliforme. Toxicon 21, 467-473.

Gelderblom, W.C.A., Thiel, P.G., Marasas, W.F.O., van der Merwe, K.J., 1984. Natural occurrence of fusarin C, a mutagen produced by Fusarium moniliforme, in corn. J. Agric. Food Chem. 32, 1064-1067.

Glenn, A.E., 2007. Mycotoxigenic Fusarium species in animal feed. Animal Feed Sci. Tech. 137, 213-240.

Glenn, A.E., Zitomer, N.C., Zimeri, A.M., Williams, L.D., Riley, R.T., Proctor, R.H., 2008. Transformation-mediated complementation of a FUM gene cluster deletion in Fusarium verticillioides restores both fumonisin production and pathogenicity on maize seedlings. Mol. Plant Microbe Interact. 21, 87-97.

Gonzalez, H.H., Martinez, E.J., Pacin, A.M., Resnik, S.L., Sydenham, E.W., 1999. Natural co-occurrence of fumonisins, deoxynivalenol, zearalenone and aflatoxins in field trial corn in Argentina. Food Addit. Contam. 16, 565-569.

Graziani, S., Vasnier, C., Daboussi, M.J., 2004. Novel polyketide synthase from Nectria haematococca. Appl. Environ. Microbiol. 70, 2984-2988.

Irizarry, R.A., Hobbs, B., Collin, F., Beazer-Barclay, Y.D., Antonellis, K.J., Scherf, U., Speed, T.P., 2003. Exploration, normalization, and summaries of high density oligonucleotide array probe level data. Biostatistics 4, 249-264.

Keller, N.P., Turner, G., Bennett, J.W., 2005. Fungal secondary metabolism - from biochemistry to genomics. Nat. Rev. Microbiol. 3, 937-947.

Khaldi, N., Seifuddin, F.T., Turner, G., Haft, D., Nierman, W.C., Wolfe, K.H., Fedorova, N.D., 2010. SMURF: genomic mapping of fungal secondary metabolite clusters. Fungal Gen. Biol. 47, 736-741.

Khaldi, N., Wolfe, K.H., 2011. Evolutionary origins of the fumonisin secondary metabolite gene cluster in Fusarium verticillioides and Aspergillus niger. Int. J. Evolut. Biol. 2011, 1-7.

Kleigrewe, K., Aydin, F., Hogrefe, K., Piecuch, P., Bergander, K., Wurthwein, E.U., Humpf, H.U., 2012. Structure elucidation of new fusarins revealing insights in the rearrangement mechanisms of the fusarium mycotoxin Fusarin C. J. Agric. Food Chem. May 5, 2012.

Kroken, S., Glass, N.L., Taylor, J.W., Yoder, O.C., Turgeon, B.G., 2003. Phylogenomic analysis of type I polyketide synthase genes in pathogenic and saprobic ascomycetes. Proc. Natl. Acad. Sci. 100, 15670-15675.

Kurobane, I., Vining, L.C., McInnes, A.G., Gerber, N.N., 1980. Metabolites of Fusarium solani related to dihydrofusarubin. J. Antibiot. 33, 1376-1379.

Leslie, J.F., Plattner, R.D., Desjardins, A.E., Klittich, C.J.R., 1992. Fumonisin B B $_{1}$ production by strains from different mating populations of Gibberella fujikuroi (Fusarium section Liseola). Phytopathology 82, 341-345.

Ma, L.J., van der Does, H.C., Borkovich, K.A., Coleman, J.J., Daboussi, M.J., Di Pietro, A., Dufresne, M., Freitag, M., Grabherr, M., Henrissat, B., Houterman, P.M., Kang, S., Shim, W.B., Woloshuk, C., Xie, X., Xu, J.R., Antoniw, J., Baker, S.E., Bluhm, B.H., Breakspear, A., Brown, D.W., Butchko, R.A., Chapman, S., Coulson, R., Coutinho, P.M., Danchin, E.G., Diener, A., Gale, L.R., Gardiner, D.M., Goff, S., HammondKosack, K.E., Hilburn, K., Hua-Van, A., Jonkers, W., Kazan, K., Kodira, C.D., Koehrsen, M., Kumar, L., Lee, Y.H., Li, L., Manners, J.M., Miranda-Saavedra, D. Mukherjee, M., Park, G., Park, J., Park, S.Y., Proctor, R.H., Regev, A., Ruiz-Roldan, 
M.C., Sain, D., Sakthikumar, S., Sykes, S., Schwartz, D.C., Turgeon, B.G., Wapinski, I., Yoder, O., Young, S., Zeng, Q., Zhou, S., Galagan, J., Cuomo, C.A., Kistler, H.C., Rep, M., 2010. Comparative genomics reveals mobile pathogenicity chromosomes in Fusarium oxysporum. Nature 464, 367-373.

Marasas, W.F., Riley, R.T., Hendricks, K.A., Stevens, V.L., Sadler, T.W., Gelineau-Van Waes, J., Missmer, S.A., Cabrera, J., Torres, O., Gelderblom, W.C., Allegood, J., Martinez, C., Maddox, J., Miller, J.D., Starr, L., Sullards, M.C., Roman, A.V., Voss, K.A., Wang, E., Merrill Jr., A.H., 2004. Fumonisins disrupt sphingolipid metabolism, folate transport, and neural tube development in embryo culture and in vivo: a potential risk factor for human neural tube defects among populations consuming fumonisin-contaminated maize. J. Nutr. 134, 711-716.

Medentsev, A.G., Akimenko, V.K., 1998. Naphthoquinone metabolites of the fungi. Phytochemistry 47, 935-959.

Mogensen, J.M., Moller, K.A., von Freiesleben, P., Labuda, R., Varga, E., Sulyok, M., Kubatova, A., Thrane, U., Andersen, B., Nielsen, K.F., 2011. Production of fumonisins B2 and B4 in Tolypocladium species. J. Ind. Microbiol. Biotechnol. 38.

Morgavi, D.P., Riley, R.T., 2007. An historical overview of field disease outbreaks known or suspected to be caused by consumption of feeds contaminated with Fusarium toxins. Animal Feed Sci. Tech. 137, 201-212.

Myung, K., Zitomer, N.C., Duvall, M., Glenn, A., Riley, R.T., Calvo, A.M., 2011. The conserved global regulator VeA is necessary for symptom production and mycotoxin synthesis in maize seedlings by Fusarium verticillioides. Plant Path., $1-9$.

Proctor, R.H., Brown, D.W., Plattner, R.D., Desjardins, A.E., 2003. Co-expression of 15 contiguous genes delineates a fumonisin biosynthetic gene cluster in Gibberella moniliformis. Fungal Genet. Biol. 38, 237-249.

Proctor, R.H., Busman, M., Seo, J.A., Lee, Y.W., Plattner, R.D., 2008. A fumonisin biosynthetic gene cluster in Fusarium oxysporum strain 0-1890 and the genetic basis for B versus C fumonisin production. Fungal Genet. Biol. 45, 1016-1026.

Proctor, R.H., Butchko, R.A., Brown, D.W., Moretti, A., 2007. Functional characterization, sequence comparisons and distribution of a polyketide synthase gene required for perithecial pigmentation in some Fusarium species. Food Addit. Contam. 24, 1076-1087.

Proctor, R.H., Desjardins, A.E., Plattner, R.D., Hohn, T.M., 1999. A polyketide synthase gene required for biosynthesis of fumonisin mycotoxins in Gibberella fujikuroi mating population A. Fungal Genet. Biol. 27, 100-112.

Proctor, R.H., McCormick, S.P., Alexander, N.J., Desjardins, A.E., 2009. Evidence that a secondary metabolic biosynthetic gene cluster has grown by gene relocation during evolution of the filamentous fungus Fusarium. Mol. Microbiol. 74, 11281142.

Proctor, R.H., Plattner, R.D., Brown, D.W., Seo, J.A., Lee, Y.W., 2004. Discontinuous distribution of fumonisin biosynthetic genes in the Gibberella fujikuroi species complex. Mycol. Res. 108, 815-822.

Shwab, E.K., Keller, N.P., 2008. Regulation of secondary metabolite production in filamentous ascomycetes. Mycol. Res. 112, 225-230.

Sims, J.W., Fillmore, J.P., Warner, D.D., Schmidt, E.W., 2005. Equisetin biosynthesis in Fusarium heterosporum. Chem. Commun., 186-188.

Sondergaard, T.E., Hansen, F.T., Purup, S., Nielsen, A.K., Bonefeld-Jorgensen, E.C. Giese, H., Sorensen, J.L., 2011. Fusarin C acts like an estrogenic agonist and stimulates breast cancer cells in vitro. Toxicol. Let. 205, 116-121.

Song, Z., Cox, R.J., Lazarus, C.M., Simpson, T.J., 2004. Fusarin C biosynthesis in Fusarium moniliforme and Fusarium venenatum. Chembiochem 5, 1196-1203.

Stipanovic, R.D., Puckhaber, L.S., Liu, J., Bell, A.A., 2011a. Phytotoxicity of fusaric acid and analogs to cotton. Toxicon 57, 176-178.

Stipanovic, R.D., Wheeler, M.H., Puckhaber, L.S., Liu, J., Bell, A.A., Williams, H.J., 2011b. Nuclear Magnetic Resonance (NMR) studies on the biosynthesis of fusaric acid from Fusarium oxysporum f. sp. vasinfectum. J. Agric. Food Chem. 59, 5351-5356.

Studt, L., Wiemann, P., Kleigrewe, K., Humpf, H.U., Tudzynski, B., 2012. Biosynthesis of fusarubins accounts for pigmentation of Fusarium fujikuroi perithecia. Appl. Environ. Micro. Epub date:2012/04/12.

Tuite, J., 1969. Plant Pathological Methods: Fungi and Bacteria. Burgess Publishing Company, Minneapolis.

Turgeon, B.G., Garber, R.C., Yoder, O.C., 1987. Development of a fungal transformation system based on selection of sequences with promoter activity. Mol. Cell. Biol. 7, 3297-3305.

Watanabe, A., Fujii, I., Sankawa, U., Mayorga, M.E., Timberlake, W.E., Ebizuka, Y. 1999. Re-identification of Aspergillus nidulans $w A$ gene to code for a polyketide synthase of naphthopyrone. Tet. Lett. 40, 91-94.

Wiemann, P., Willmann, A., Straeten, M., Kleigrewe, K., Beyer, M., Humpf, H.U. Tudzynski, B., 2009. Biosynthesis of the red pigment bikaverin in Fusarium fujikuroi: genes, their function and regulation. Mol. Microbiol. 72, 931-946.

Wu, F., 2007. Measuring the economic impacts of Fusarium toxins in animal feeds. Animal Feed Sci. Tech. 137, 363-374.

Yoder, O.C., Turgeon, B.G., 2001. Fungal genomics and pathogenicity. Curr. Opin Plant Biol. 4, 315-321. 